\title{
Short-term physiological responses to drought stress in seedling of tropical and temperate maize (Zea mays L.) cultivars
}

\author{
Pu Zhao, ${ }^{1,2}$ Jin Wang, ${ }^{3}$ Niran Juntawong, ${ }^{4}$ Chokechai Aekatasanawan, ${ }^{5}$ Prasart Kermanee, ${ }^{4}$ \\ Sittiruk Roytrakul, ${ }^{6}$ Yinsuo Jia, ${ }^{2}$ Chunhong $\mathrm{Ma}^{2}$ \\ ${ }^{1}$ Interdisciplinary Graduate Program in Bioscience, Faculty of Science, Kasetsart University, Bangkok, Thailand; \\ ${ }_{2}^{2}$ Institute of Genetics and Physiology, Hebei Academy of Agriculture and Forestry Sciences, Plant Genetic Engineering \\ Center of Hebei Province, China; ${ }^{3}$ Institute of Shijiazhuang Fruit Tree, Hebei Academy of Agriculture and Forestry \\ Sciences, China; ${ }^{4}$ Department of Botany, Kasetsart University, Thailand; ${ }^{5}$ National Corn and Sorghum Research \\ Center, Faculty of Agriculture, Kasetsart University, Thailand; ${ }^{6}$ Genome technology Research Unit, National Center \\ for Genetic Engineering and Biotechnology, Thailand
}

Correspondence: Ma Chunhong, Institute of Genetics and Physiology, Hebei Academy of Agriculture and Forestry Sciences, Plant Genetic Engineering Center of Hebei Province, No.598 West Heping Road, Shijiazhuang 050051, Hebei, China.

Tel.: +86.0311.87652128 - Fax: +86.0311.87652119.

E-mail: mch0609@126.com

Key words: Maize; Drought; Tropical and temperate hybrid; Stomatal conductance.

Contributions: PZ developed the original idea and the protocol, drafted and analyzed data, wrote the manuscript; JW analyzed data, drafted and revised content; NJ, CA, PK and YJ provied experimental materials, equipment and manuscript correction; $\mathrm{CM}$ revised critically for important intellectual and final approval of the version to be published.

Conflict of interest: the authors declare no potential conflict of interest.

Funding: funding provided by National Key R\&D Program of China (2017YFD0300400), International Science and Technology Cooperation Project of Hebei Province (17396301D)(17396311D), Technology Innovation Program of Hebei Academy of Agriculture and Forestry (F18C10002).

Acknowledgements: special thanks are due to graduate school, Kasetsart University for providing scholarship and support my research. Additional funding provided by National Key R\&D Program of China (2017YFD0300400), International Science and Technology Cooperation Project of Hebei Province (17396301D)(17396311D), Technology Innovation Program of Hebei Academy of Agriculture and Forestry (F18C10002) is highly acknowledged.

Received for publication: 27 December 2018.

Revision received: 26 February 2019.

Accepted for publication: 27 February 2019.

(C) Copyright P. Zhao et al., 2019

Licensee PAGEPress, Italy

Journal of Biological Research 2019; 92:8015

doi:10.4081/jbr.2019.8015

This article is distributed under the terms of the Creative Commons Attribution Noncommercial License (by-nc 4.0) which permits any noncommercial use, distribution, and reproduction in any medium, provided the original author(s) and source are credited.

\begin{abstract}
Understanding of the response of tropical and temperate maize (Zea mays L.) to drought is the first step for tolerant temperate maize improvement. Eight maize hybrids were used to investigate physiology responses under drought stress, four of them were tropical maize and the others were temperate maize. Results showed that there were different drought tolerances but similar trends in both tropical maize and temperate maize. Gas exchange parameters revealed different strategies of maize under the stress. In our study, most of the temperate hybrids maintained open stomata to keep a higher photosynthesis rate at the beginning of stress, while the other hybrids decreased stomatal conductance. Compared to temperate maize, the tropical maize had higher antioxidase activity and greater physiological parameter variation among hybrids. KS5731 and ZD309 had stronger drought resistance among tropical and temperate maize hybrids separately. Tolerant hybrids maintained active photosynthesis, have higher osmotic adjustment ability and antioxidase activities but lower malonaldehyde content than the sensitive ones. Our results led to a better understanding of the physiological responses of tropical and temperate maize plants to drought stress and may provide an insight of breeding for drought resistance in maize.
\end{abstract}

\section{Introduction}

Drought is one of the major constraints for plant productivity and has become increasingly serious globally. Maize is known to be susceptible to even mild or moderate drought particularly at the beginning of plant growth, drought may also dramatically limit the biomass production and the photosynthetic ability of leaves and thus indirectly negatively affect the formation of reproductive organs and yield parameters. ${ }^{1-3}$ Drought stress occurred during maize growth period may hamper the nitrogen and water use efficiencies. $^{4}$

Drought-related physiological and metabolic changes might be helpful in determining the sensitivity or tolerance of a plant under water deficit conditions and can be used as stress indicators. At present, research on maize drought resistance has been carried out world widely, researchers have found many physiological indicators related to drought tolerance, such as relative water con- 
tent (RWC), photosynthesis related indicators, MDA, proline, polysaccharides, antioxidant enzymes ${ }^{5}$ Efeoğlu et al. ${ }^{6}$ conducted a 12 days of drought stress to maize seedling, the results showed that RWC, photosynthetic parameters and chlorophyll decreased in all cultivars by drought whereas anthocyanin and proline contents increased. Messina et ll. $^{7}$ found that the transpiration response of maize hybrids to drought stress has genotypic diversity. Many genes that are expressed differentially in responses to drought stress affect photosynthetic systems and hormone biosynthesis. Noman et al. ${ }^{8}$ found that drought stress could enhance the superoxide dismutase (SOD) and peroxidase (POD) activities in maize.

Due to a unique genome structure and continuous human selection for over 7000 years, maize can be divided into two main groups, tropical and temperate maize. And it is one of the most resilient plant species can grow at different altitudes and climates. ${ }^{9}$ Significant differences in artificial and natural selection involved in maize domestication and improvement have contributed to its adaptation to different agro-climatic zones. Productivity of maize in the tropics is much lower than in temperate areas. When maize varieties adapted to tropical latitudes are grown in temperate environments such as the US Corn Belt, they flower later and produce little or no grain, but have higher total biomass yields compared to modern commercial maize grain hybrids. Compared with temperate maize, the tropical maize has high resistance to various of disease and insect pests and also have better tolerance to abiotic stresses. ${ }^{10}$ Detailed knowledge of maize germplasm, particularly temperate and tropical types, is important not only for parental selection but also for genetic analysis and breeding.

The presented study attempts to enhance our knowledge of maize responses to drought at the early developmental stages in tropical and temperate maize, and to determine the physiological indicator traits that can discriminate maize lines for their tolerance under drought stress. The research result of germplasm drought resistance mechanism from different sources will provide a theoretical basis for future breeding practice.

\section{Materials and Methods}

\section{Plant material}

Eight maize hybrids were used for this work. Zhengdan 958 (ZD958), Denghai 605 (DH605), Nonghua101 (NH101), Zhengdan 309 (ZD309) are temperate maize. NS3, SW2301, SW4452, KS5731 are tropical maize and were supplied by Kasetsart University, Thailand.

\section{Growth conditions and drought stress treatments}

The seeds were cultured with $1 / 2$ Hoagland nutrient solution under greenhouse condition. Temperatures were between $25^{\circ} \mathrm{C}$ to $27^{\circ} \mathrm{C}$ and relative humidity was $60 \pm 5 \%$. Maize plants were watered with nutrient solution daily until application of stress. V3 stage plants were treated with $15 \%$ PEG for three days. The drought stress samples were collected at day $0,1,2,3$.

\section{Physiology measurements}

The samples were cut from the middle of the 4th leaf to measure the fresh mass (FM), saturated mass (SM) were measured after the same leaf parts hydrated in the dark for $5 \mathrm{~h}$. These leaves were oven-dried at $80^{\circ} \mathrm{C}$ for $48 \mathrm{~h}$ to determine dry mass (DM). The RWC was calculated as $100 \times(\mathrm{FM}-\mathrm{DM}) /(\mathrm{SM}-\mathrm{DM}){ }^{11}$

Leaf membrane permeability was assessed by the electrolyte leakage percentage and measured by conductivity meter. For measurement of membrane permeability, $0.2 \mathrm{~g}$ leaf was cut into filaments about $1 \mathrm{~mm}$ and soaked in $15 \mathrm{ml}$ distilled water for $24 \mathrm{~h}$. Conductivity of the solution was determined at the end of incubation by DDSJ-308A conductivity meter, recorded as $\mathrm{EC}_{1}$. After $30 \mathrm{mins}$ boiling water bath, it was measured again and recorded as $\mathrm{EC}_{2}$. Membrane permeability was calculated as percentage of $\mathrm{EC}_{1} / \mathrm{EC}_{2}{ }^{12}$

Proline, malonaldehyde (MDA), the activities of POD, catalase (CAT) were extracted by using biochemical kit (Suzhou Comin Biotechnology Co., Ltd., Suzhou, China) and measured spectrophotometrically (Tecan infinite 200 Pro, Männedorf, Switzerland). ${ }^{13}$

The middle part of the fully expanding leaf was used for the measurements of transpiration rate $(\mathrm{E})$, net photosynthesis rate $(\mathrm{P} n)$, stomatal conductance $(\mathrm{Gs})$ and intercellular $\mathrm{CO} 2$ concentration $(\mathrm{C} i)$. These leaf parameters were measured in situ by the portable gas exchange system CIRAS-3 (PP Systems Ltd., USA).

\section{Data process}

All data were processed by the software of Microsoft Excel 2007 and OriginPro 9.1, analyzed by SPSS19.0 with the method of ANOVA and multiple comparisons (Duncan's Multiple Range Test).

\section{Results}

\section{Relative water content of leaves of drought stressed maize}

The PEG treatment significantly reduces the RWC of maize. SW2301, DH605 and NH101 decreased slightly on the first day after treatment, and then decrease significantly $(\mathrm{P}<0.05)$ on the second day. KS5731 remained stable for the first two days of treatment, but fell to $85.4 \%$ on the third day. NS3 had a gradual decreasing trend from $90.3 \%$ to $65.0 \%$. The RWC of SW4452 decreased sharply on the first day after treatment. After 3 days of drought treatment, the RWC of KS5731 and ZD309 was still above $80 \%$, of which KS5731 was the highest; SW4452 reduced to $54.9 \%$, the lowest among all hybrids (Figure 1).

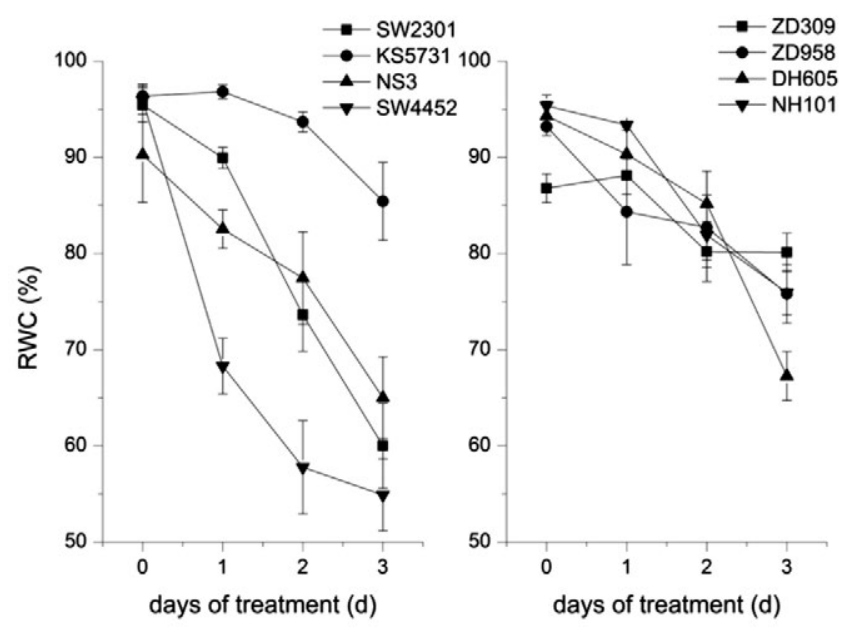

Figure 1. Relative water content of different maize hybrids under drought treatment. RWC, relative water content. 


\section{Gas exchange of leaves of drought stressed maize}

The initial net photosynthesis rate $(\mathrm{P} n)$ of tropical maize seedlings showed decline trend after treatment. In temperate maize, the $\mathrm{P} n$ raised for a short time after drought stress, and then reduce to a similar level around $3.3-7.3 \mu \mathrm{mol} \mathrm{m} \mathrm{m}^{-2} \mathrm{~s}^{-1}$. After 3 days of treatment, Pn of KS5731 was still the highest of all, other tropical maize decreased by 7.7-10.2 $\mu \mathrm{mol} \mathrm{m} \mathrm{m}^{-2} \mathrm{~s}^{-1}$, while temperate maize decreased 4.9-8.5 $\mu \mathrm{mol} \mathrm{m} \mathrm{m}^{-2} \mathrm{~s}^{-1}$ (Figure 2A). The stomatal conductance (Gs) and transpiration rate (E) of maize under drought stress showed a similar trend to the $\mathrm{P} n$. After 3 days of simulated drought stress, the Gs of KS5731 decreased by $50.4 \mathrm{mmol} \mathrm{m}^{-2} \mathrm{~s}^{-1}$, and other tropical hybrids were lower than $25.9 \mathrm{mmol} \mathrm{m}^{-2} \mathrm{~s}^{-1}$. Temperate hybrids also fell to $12.5-28 \mathrm{mmol} \mathrm{m}^{-2} \mathrm{~s}^{-1}$ after treatment (Figure 2B). And transpiration rate of all hybrids had fallen below 0.95 mmol m${ }^{-2} \mathrm{~s}^{-1}$, while KS5731 was still the highest. The transpiration rate of temperate hybrids has a consistent response to drought treatment, all of them decreased drastically on the second day (Figure $2 \mathrm{C}$ ). After 3 days of drought treatment, intercellular $\mathrm{CO}_{2}$ concentration $(\mathrm{C} i)$ of most the tropical maize hybrids increased, and no significant changes in temperate maize (Figure 2D).

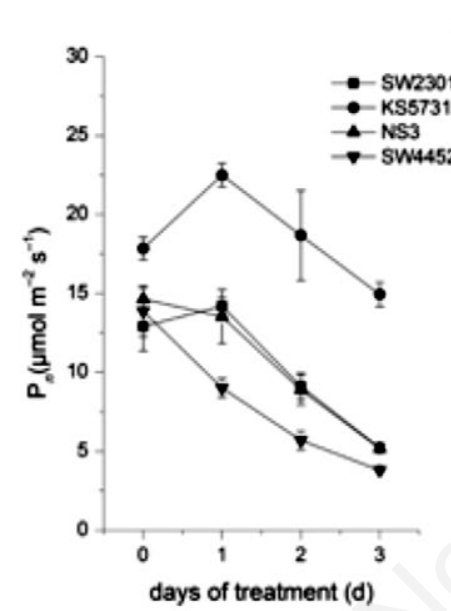

A

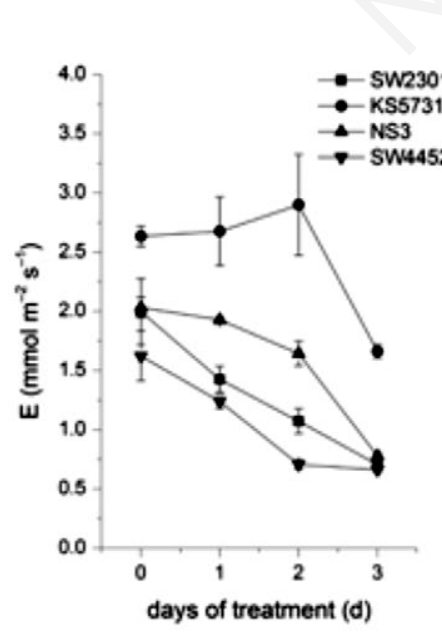

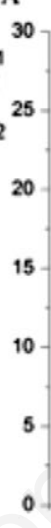

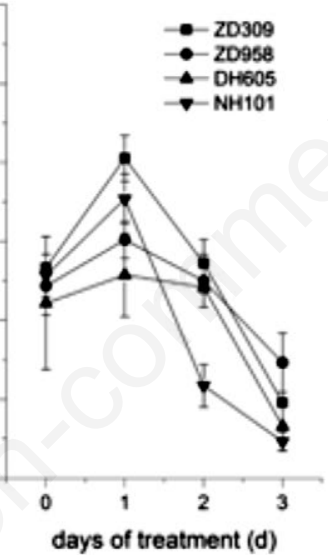

C

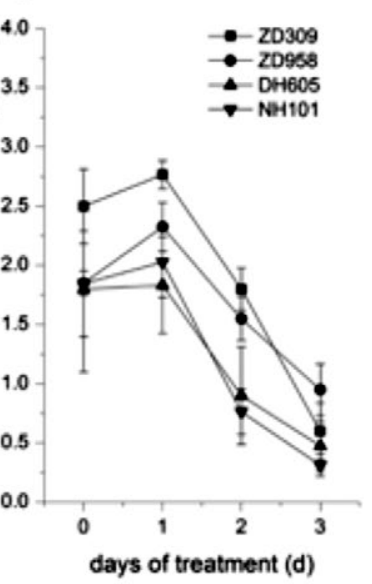

\section{Cell membrane stability and osmotic adjustment}

The electrolyte leakage percentage of leaves increased under drought treatment. KS5731, NS3, ZD958, DH605 and NH101 increased significantly $(\mathrm{P}<0.05)$ after 3 days of treatment. NS3 and SW4452 leakage percentage remain under 50\% (Table 1).

The MDA content of leaves under drought stress increased at the beginning and then decreased. The MDA of SW2301 and SW4452 continued to increase by 2 days after treatment, while NS3 and all temperate hybrids increased only on the first day, and then gradually declined. In tropical hybrids, SW2301 and SW4452 reached the highest MDA content in the second day as $15.5 \mathrm{nmol}$ $\mathrm{g}^{-1}$ and $15.8 \mathrm{nmol} \mathrm{g}^{-1}$ respectively. Temperate hybrids ZD309 and DH605 peaked $13.4 \mathrm{nmol} \mathrm{g}^{-1}$ on the first day after treatment (Figure 3A). After 3 days of treatment, the MDA of most hybrids drops to the pre-treatment level.

The content of proline showed a gradual increase trend after drought treatment. Before treatment, the proline in temperate hybrids was higher, among which ZD309 and ZD958 were the most prominent. After 3 days of treatment, SW4452 had the largest increment of $59.9 \mu \mathrm{g} \mathrm{g}^{-1}$ (Figure 3B).
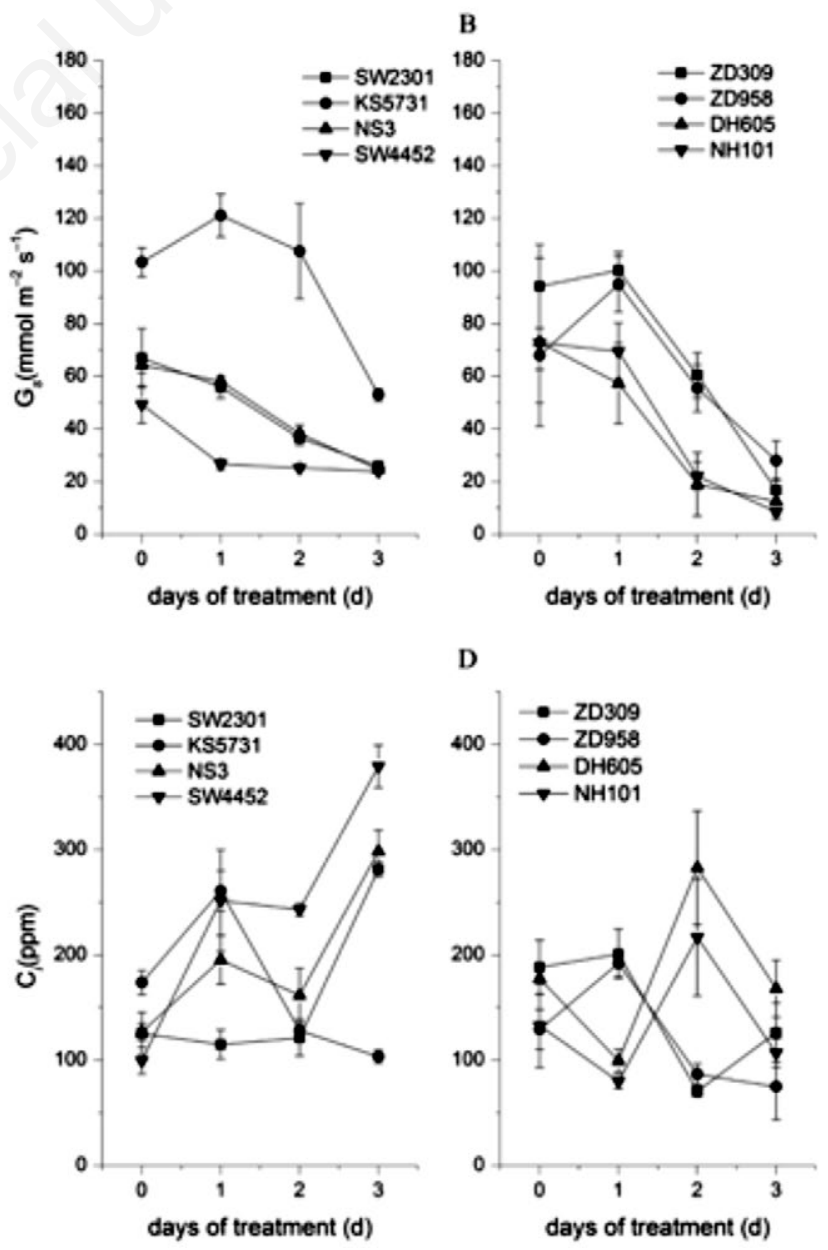

Figure 2. (A) The net photosynthetic rate (Pn); (B) stomatal conductance (Gs); (C) net transpiration rate (E); (D) intercellular CO2 concentration $(\mathrm{Ci})$ in the leaves of drought stressed maize. 


\section{Antioxidase activities in the leaves of drought stressed maize}

The CAT activity in the leaves of maize seedlings increased rapidly after drought treatment, while ZD309 was an exception. This growth was a short-term effect. The CAT activity of most hybrids (except KS5731) declined on the third day of treatment but still higher than that before treatment. The CAT activity of tropical hybrids responded to drought stress more obviously, and the highest activities could be 1842.6-2477.7 $\mathrm{U} \mathrm{g}^{-1}$. The response of temperate hybrids was not obvious. The highest activity of ZD958 was only $1675.8 \mathrm{U} \mathrm{g}^{-1}$ (Figure 4A). The response of POD activity of different hybrids to drought varied greatly. The POD activity of most hybrids increased after treatment, but the rate of increase was less than that of CAT. The POD activity of KS5731, SW4452 and NH101 decreased in the first day of treatment, and then gradually increased. The initial POD activity of tropical hybrids was between 3365-4083 $\mathrm{U} \mathrm{g}^{-1}$ and higher than that of most temperate hybrids. SW2301, NS3 and SW4452 had relatively high POD activity after 3 days of treatment (Figure 4B).

\section{Discussion}

In our study, drought could significantly $(\mathrm{P}<0.05)$ reduce the maize RWC. Many studies had shown that the RWC of plant leaves decreased after PEG induced drought stress. Siddique et al. ${ }^{14}$ found that drought stress significantly reduced RWC for $43 \%$ during wheat development, similar results had been confirmed in barley, rice, peanut and other crops. ${ }^{15-17}$ The RWC of KS5731 and ZD309 declined slowly, suggesting that the hybrids in both tropical and temperate maize with stronger drought resistance had a strong water retention capacity.

In gas metabolism such as carbon assimilation, respiration and transpiration, stomata control the fluxes of gases between the atmosphere and the plant interior. ${ }^{18}$ The net photosynthesis rate, transpiration rate and stomatal conductance of maize seedlings had same change trend after treatment and all decreased at $3^{\text {rd }}$ day, indicating that drought caused stomatal closure, and absorption of $\mathrm{CO}_{2}$ was also inhibited. The deleterious effect of drought maybe targeted photosynthesis. ${ }^{19,20}$ Most of the temperate maize hybrids maintained open stomatal and efficient transpiration. This situation may lead to a greater water loss but maintained efficient photosynthesis. It's a risky strategy of maintaining stomata open under drought conditions, however it would be beneficial under a short time, as the plant would be able to retain a relatively normal growth capacity. ${ }^{1}$ The gas exchange index of KS5731 and ZD958 indicate that they have good resistance under drought conditions.

Both electrolyte leakage percentage and MDA can reflect the damage degree of cell membrane, usually the lower index value represents the stronger drought resistance. In terms of electrolyte leakage, most of the tropical maize hybrids, KS5731, NS3 and SW4452 have good cell membrane stability under drought stress, suggesting that tropical maize has strong cell membrane stability. MDA could represent the degree of lipid peroxidation. ${ }^{21}$ The MDA content of KS5731, ZD309, ZD958 and NH101 was reduced after drought treatment, suggesting that they had strong lipid antioxidant and self-healing capacity under stress. The proline of SW4452, ZD309, ZD958 and DH605 increased after treatment, which may

Table 1. Electrolyte leakage of different maize hybrids under drought treatment.

\begin{tabular}{lccc} 
Hybrids & \multicolumn{3}{c}{$\begin{array}{c}\text { Electrolyte leakage (\%) } \\
\text { 2d }\end{array}$} \\
Od & 3d \\
KW501 & $53.4 \pm 9.8^{\mathrm{a}}$ & $63.8 \pm 14.8^{\mathrm{a}}$ & $63.3 \pm 4.2^{\mathrm{a}}$ \\
\hline NS3 & $22 \pm 2.5^{\mathrm{a}}$ & $26.7 \pm 8.4^{\mathrm{a}}$ & $50.1 \pm 1.3^{\mathrm{b}}$ \\
\hline SW4452 & $28.9 \pm 4^{\mathrm{a}}$ & $43.3 \pm 7.9^{\mathrm{ab}}$ & $47.8 \pm 10.6^{\mathrm{b}}$ \\
\hline ZD309 & $41.5 \pm 6.1^{\mathrm{a}}$ & $46.2 \pm 4.4^{\mathrm{a}}$ & $49.5 \pm 5.7^{\mathrm{a}}$ \\
ZD958 & $43.2 \pm 5.8^{\mathrm{a}}$ & $52.9 \pm 2.4^{\mathrm{a}}$ & $50.2 \pm 8^{\mathrm{a}}$ \\
\hline DH605 & $39.9 \pm 4.3^{\mathrm{a}}$ & $53.7 \pm 9^{\mathrm{a}}$ & $77.9 \pm 10^{\mathrm{b}}$ \\
NH101 & $41.2 \pm 14.3^{\mathrm{a}}$ & $46.7 \pm 1.9^{\mathrm{ab}}$ & $65.9 \pm 5^{\mathrm{b}}$ \\
\hline
\end{tabular}

a, b represent significant differences in the same hybrid $(\mathrm{P}<0.05)$.
A

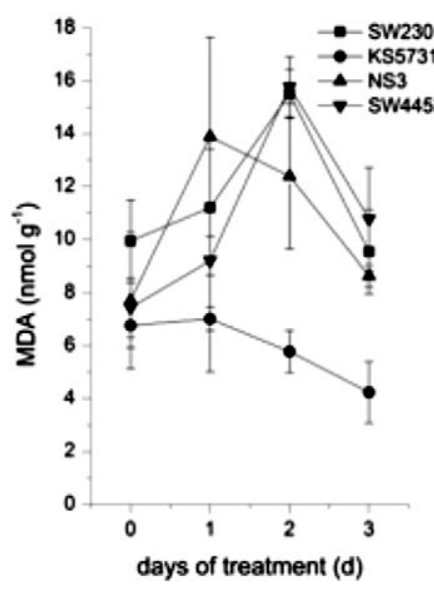

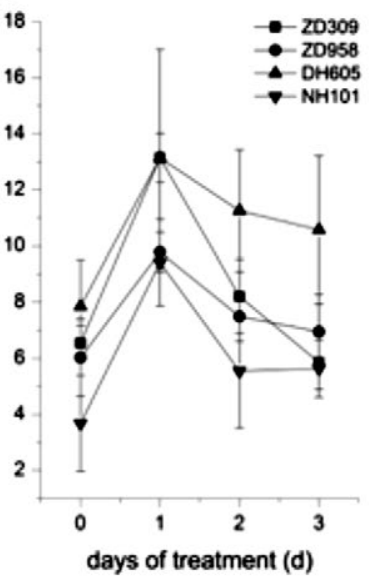

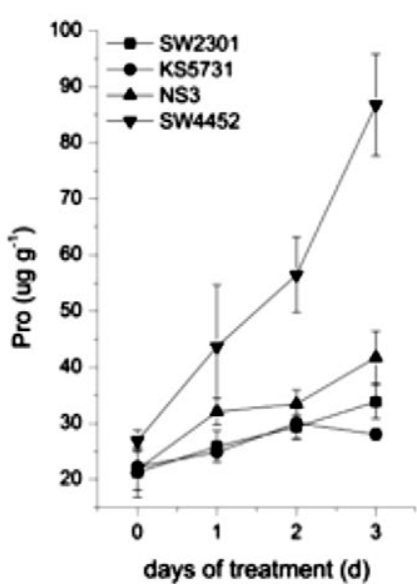

B

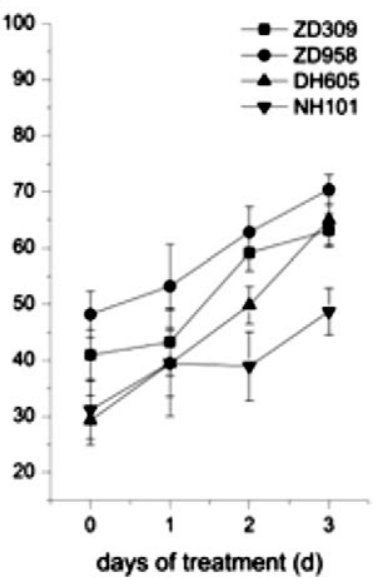

Figure 3. The malonaldehyde (A) and proline (B) content in the leaves of drought stressed maize. 


\section{A}

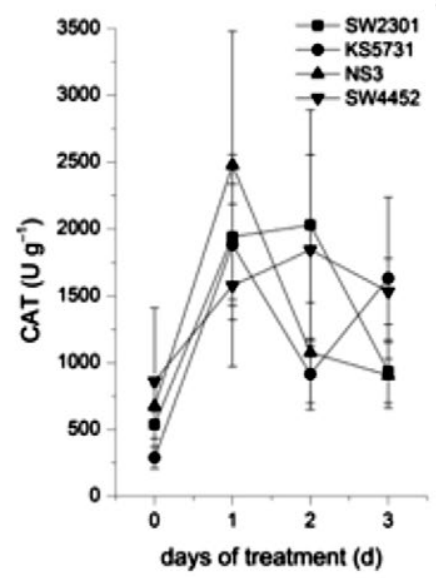

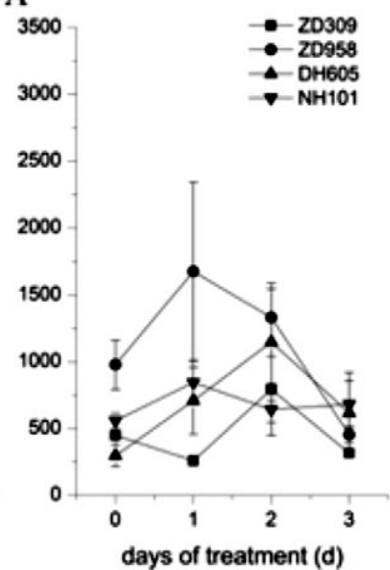

B

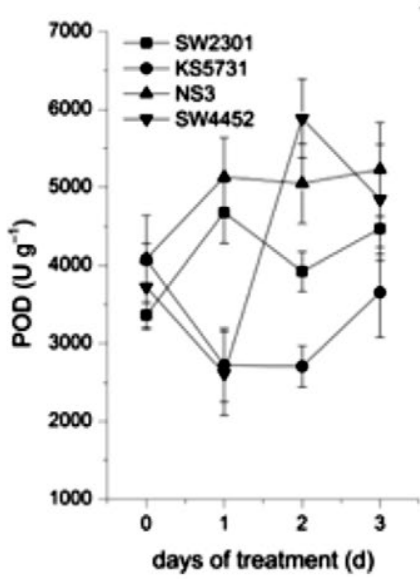

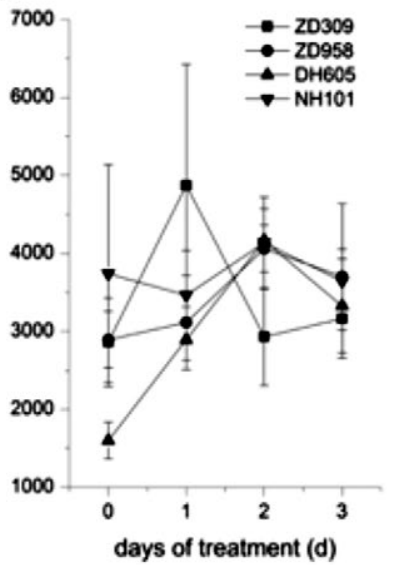

Figure 4. The activities of antioxidant enzymes in the leaves of drought stressed maize.

suggest these four hybrids have advantages in osmotic regulation. Some researchers speculated the accumulation of proline may be the adaptation of maize to drought. ${ }^{22,23}$ Our results showed that the proline level had a negative trend with injury parameters (MDA and electrolyte leakage) under drought stress, indicating proline is an important resistance factor in the early stage of drought.

Studies had shown that drought stress induced an increase in reactive oxygen of plant leaves, accompanied by the antioxidant system activation. ${ }^{24-26}$ Wang et al. ${ }^{27}$ found that activities of POD and CAT were increased under light drought stress, while decreased under higher level drought stress. Our results also confirmed this phenomenon, activities of both enzymes in most maize seedlings shortly increased after drought stress, but decreased as the drought duration prolong. Most antioxidase activity of the tropical maize was higher than temperate maize after three days of treatment, indicating the antioxidant system of tropical maize could be rapidly activated by drought stress and maintained for a period of time. KS5731 and SW4452 could maintain high CAT activity over a relatively long period of drought stress, suggesting that these two cultivars had some potential on drought resistance.

Temperate maize has the advantage of high yield. Tropical maize has abundant stress related genes, especially drought related genes. Tropical germplasm is a key resource to improve the genetic resiliency of temperate maize. ${ }^{28,29}$ Physiological parameters in different tropical maize hybrids showed great difference under drought stress, while the temperate maize showed a relatively consistent performance, which suggested that tropical maize had greater genetic diversity than temperate maize. Lai et al. ${ }^{30}$ found tropical maize had more unique non-redundant TEs (NRTEs) than temperate maize. The drought-related genes (such as $d h n 1$ and olcl) in tropical maize have potential roles in drought tolerance. ${ }^{31}$ As the global climate change and water shortage, it is very urgent to screen drought resistance traits from tropical maize germplasm resources.

\section{Conclusions}

The determination of drought related physiological parameters of maize hybrids showed that there were different drought tol- erances but similar responses in both tropical maize and temperate maize. The tropical maize may have greater genetic diversity than temperate maize. KS5731 and SW2301, ZD309 and DH605 have stronger drought resistance in tropical and temperate maize hybrids separately. Different strategies were used to tolerate drought stress in maize. In our study, most of the temperate hybrids maintained open stomata to keep a higher photosynthesis rate at the beginning of stress. Compared with sensitive hybrids, tolerant hybrids maintained active photosynthesis rate, had higher osmotic adjustment ability and antioxidase activities but lower MDA content. Our results led to a better understanding of the physiological responses of tropical and temperate maize plants to drought stress and may provide an insight of breeding for drought resistance in maize.

\section{References}

1. Benešová M, Holá D, Fischer L, et al. The physiology and proteomics of drought tolerance in maize: early stomatal closure as a cause of lower tolerance to short-term dehydration? PLoS One 2012;7:e38017.

2. Qingfeng M, Xinping C, David BL, et al. Growing sensitivity of maize to water scarcity under climate change. Sci Rep 2016;6:19605.

3. Lucia C, Gerardo R, Juan MH. Drought and temperature limit tropical and temperate maize hybrids differently in a subtropical region. Agro Sustain Dev 2018;38:49.

4. Ashraf U, Salim MN, Sher A, et al. Maize growth, yield formation and water-nitrogen usage in response to varied irrigation and nitrogen supply under semi-arid climate. Turk J Field Crops 2016;21:88-96.

5. Keyvan S. The effects of drought stress on yield, relative water content, proline, soluble carbohydrates and chlorophyll of bread wheat cultivars. J Anim Plant Sci 2010;8:1051-60.

6. Efeoğlu B, Ekmekçi Y, Çiçek N. Physiological responses of three maize cultivars to drought stress and recovery. S Afr J Bot 2009;75:34-42.

7. Messina CD, Sinclair TR, Hammer GL, et al. Limited-transpi- 
ration trait may increase maize drought tolerance in the US Corn Belt. Agron J 2015;107:1978-86.

8. Noman A, Ali S, Naheed F, et al. Foliar application of ascorbate enhances the physiological and biochemical attributes of maize (Zea mays L.) cultivars under drought stress. Arch Agron Soil Sci 2015;61:1659-72.

9. Hayano-Kanashiro C, Calderon-Vazquez C, Ibarra-Laclette E, et al. Analysis of gene expression and physiological responses in three Mexican maize landraces under drought stress and recovery irrigation. PloS One 2009;4:e7531.

10. Mengesha WA, Menkir A, Unakchukwu N, et al. Genetic diversity of tropical maize inbred lines combining resistance to Striga hermonthica with drought tolerance using SNP markers. Plant Breed 2017;136:338-43.

11. González L, González-Vilar M. Determination of relative water content. Handbook of plant ecophysiology techniques. Dordrecht: Springer; 2001. pp 207-212.

12. Jiang M, Zhang J. Effect of abscisic acid on active oxygen species, antioxidative defence system and oxidative damage in leaves of maize seedlings. Plant Cell Physiol 2001;42:1265-73.

13. Zhu X, Song F, Liu S. Arbuscular mycorrhiza impacts on drought stress of maize plants by lipid peroxidation, proline content and activity of antioxidant system. J Food Agric Environ 2011;9:583-7.

14. Siddique MRB, Hamid A, Islam MS. Drought stress effects on water relations of wheat. Bot Bull Acad Sin 2000;41:35-9.

15. Sharma KD, Kumar A, Verma SR. Variations in physiological traits as screening tool for drought tolerance in barley (Hordeum vulgare L.). Indian J Plant Physiol 2016;21:93-100.

16. Todaka D, Zhao Y, Yoshida T, et al. Temporal and spatial changes in gene expression, metabolite accumulation and phytohormone content in rice seedlings grown under drought stress conditions. Plant J 2017;90:61-78.

17. Shivakrishna P, Reddy KA, Rao DM. Effect of PEG-6000 imposed drought stress on RNA content, relative water content (RWC), and chlorophyll content in peanut leaves and roots. Saudi J Biol Sci 2018;25:285-9.

18. Lawson T, Simkin AJ, Kelly G, Granot D. Mesophyll photosynthesis and guard cell metabolism impacts on stomatal behaviour. New Phytol 2014;203:1064-81.

19. Liu H, Sultan MARF, Liu XL, et al. Physiological and compar- ative proteomic analysis reveals different drought responses in roots and leaves of drought-tolerant wild wheat (Triticum boeoticum). PLoS One 2015; 10:e0121852.

20. Zandalinas SI, Mittler R, Balfagón D, et al. Plant adaptations to the combination of drought and high temperatures. Physiol Plantarum 2018;162:2-12.

21. Ayala A, Muñoz MF, Argüelles S. Lipid peroxidation: production, metabolism, and signaling mechanisms of malondialdehyde and 4-hydroxy-2-nonenal. Oxid Med Cell Longev 2014; 2014:360438.

22. Serraj R, Sinclair T. Osmolyte accumulation: can it really help increase crop yield under drought conditions? Plant Cell Environ 2002;25:333-41.

23. Blum A. Osmotic adjustment is a prime drought stress adaptive engine in support of plant production. Plant Cell Environ 2017;40:4-10.

24. Sharma P, Dubey RS. Drought induces oxidative stress and enhances the activities of antioxidant enzymes in growing rice seedlings. Plant Growth Regul 2005;46:209-21.

25. Zhang M, Jin ZQ, Zhao J, et al. Physiological and biochemical responses to drought stress in cultivated and Tibetan wild barley. Plant Growth Regul 2015;75:567-74.

26. Noctor G, Mhamdi A, Foyer $\mathrm{CH}$. The roles of reactive oxygen metabolism in drought: not so cut and dried. Plant Physiol 2014; 164:1636-48.

27. Wang J, Li D, Gu L. The response to water stress of the antioxidant system in maize seedling roots with different drought resistance. Acta Bot Boreali-Occident Sin 2002;22:285-90.

28. Teixeira JEC, Weldekidan T, de Leon N, et al. Hallauer's Tuson: a decade of selection for tropical-to-temperate phenological adaptation in maize. Heredity 2015;114:229-40.

29. Liu H, Wang X, Warburton ML, et al. Genomic, transcriptomic, and phenomic variation reveals the complex adaptation of modern maize breeding. Mol Plant 2015;8:871-84.

30. Lai X, Schnable JC, Liao Z, et al. Genome-wide characterization of non-reference transposable element insertion polymorphisms reveals genetic diversity in tropical and temperate maize. BMC Genomics 2017;18:702.

31. He C, Fu J, Zhang J, et al. A gene-oriented haplotype comparison reveals recently selected genomic regions in temperate and tropical maize germplasm. PloS One 2017;12:e0169806. 